\title{
Synthesis and properties of poly(urethane-imide) interpenetrating network membranes
}

\author{
Mei-Hui Tsai ${ }^{\mathrm{a}}$, Shih-Liang Huang ${ }^{\mathrm{a}}$, Shu-Jhuan Liu ${ }^{\mathrm{a}}$, \\ Chiou-Jey Chen ${ }^{\mathrm{a}}$, Pei-Jyun Chen ${ }^{\mathrm{a}}$, Shih-Hsiung Chen ${ }^{\mathrm{b}}$ \\ ${ }^{a}$ Department of Chemical and Materials Engineering, National Chin-Yi University of Technology, \\ Taichung 411, Taiwan, ROC \\ Tel. +886-4 23924505, ext.7508; Fax+886-4 23926617; email: huangsl@ncut.edu.tw \\ ${ }^{b}$ Department of Environmental Engineering and Healty Chia-Nan University of Pharmacy and Science, \\ Tainan 717, Taiwan, ROC
}

Received 31 July 2007; accepted revised 28 September 2007

\begin{abstract}
Poly(urethane-imide) (PUI) membranes are prepared by blending polyurethane (PU) prepolymer with different ratio of poly(amide acid) (PAA). PU prepolymer are synthesized by two-stages process with hydroxyl-terminated polybutadiene (HTPB), 4,4'-dicyclohexylmethane diisocyanate $\left(\mathrm{H}_{12} \mathrm{MDI}\right)$ and 1,4-butane diol $(1,4-\mathrm{BD})$. While 4,4'-diaminodiphenyl ether (ODA) and 3,3'-4,4'-benzophenonetetracarboxylic dianhydride (BTDA) are reacted to forming the polyimide (PI) oligomer solution of poly(amide acid) (PAA). IPN structures are formed through reaction between PU prepolymer and PAA and unsaturated $\mathrm{C}=\mathrm{C}$ double bond between different HTPB segment of PU. All PUI membranes show three steps of weight loss curves and PI shows one step weight loss curve by thermogravimetric analysis (TGA). Compositions lower than $50 \mathrm{wt} . \%$ of PU content (0.5-PUI) possess better compatibility between PU and PI and the glass transition temperature of PU hard segment (Tgh) of PUI membranes disappeared. The Tgh values, maximum degradation temperature and char yield of PUI membranes are increased as the increase of PI content. The gas permselectivities of 0.5-PUI are 12 times than that of pure PI.
\end{abstract}

Keywords: Polyimide; Polyurethane; Poly(urethane-imide); DMA; TGA; Morphology; Gas separation

\footnotetext{
*Corresponding author.
}

Presented at the Fourth Conference of Aseanian Membrane Society (AMS 4), 16-18 August 2007, Taipei, Taiwan. 


\section{Introduction}

Polyimide materials possess superior heat durability, chemical stability, mechanical strength, dielectric properties and many usages in semiconductor industries. Others are ultra thinning film formation and high gas separation properties, which is an important aspect of gas separation's materials [1-5]. While the low gas permeability of polyimide due to its densed structure and cannot provide economical usage. HTPB used as the polyol of PU because HTPB possesses low temperature flexibility and lower surface energy, which induces a superhydrophobic surface of very soft PU polymer [6-9]. HTPB-based PU exhibits low tensile strength and a breaking strength at room temperature. PU material possesses superior viscolasticity, tenacity and abrasion resistance. In general, the gas permeabilities of PU materials are high. While the gas selectivity, mechanical properties and thermal stability of PU membranes are low and cannot be used for the separation performances [10-12]. For the combination of these two materials' superiority, add PI to PU to expand their respective characteristics and expect the best separation performances to be obtained. We hope that the prepared PI/PU hybrids can be suited to separating gases and increasing the economical efficiency. There are many reports on the PI/PU hybrid membranes for the studies of heat, mechanical properties and phase separation [13-20], while rarely study on the HTPB-based PU and gas separation. In this study, series of PI/PU hybrid membranes are prepared and studies on the phase separation, thermal stability and $\mathrm{O}_{2} / \mathrm{N}_{2}$ gas separation performance.

\section{Experiment}

\subsection{Materials}

4,4'-Diaminodiphenylether (ODA, 98\%) from Lancaster is dried in a vacuum oven at $125^{\circ} \mathrm{C}$ for $24 \mathrm{~h}$ prior to use. $3,3^{\prime}-4,4^{\prime}$-Benzophenonetetracarboxylic dianhydride (BTDA) from Acros Organics is purified by recrystallization from acetic anhydride and then dried in a vacuum oven at $125^{\circ} \mathrm{C}$ overnight. Hydroxyl-terminated polybutadiene (HTPB) (equivalent weight $1333 \mathrm{~g}$, average functionality of 2.2 , R- 45 of Arco Co.), 4,4'-dicyclohexylmethane diisocyanate $\left(\mathrm{H}_{12} \mathrm{MDI}\right)$ (Desmodue $\mathrm{W}$ of Mobay $\mathrm{Co}$.), and 1,4-butane diol(1,4-BD) are used to synthesize PU prepolymer. $\mathrm{N}$-methyl-2-pyrrolidone (NMP) from Tedia Company is dehydrated with molecular sieves.

\subsection{Preparation of membranes}

\subsubsection{Synthesis of poly (amide acid)}

Purified ODA and suitable amount of NMP are added to the three necked bottle and purged with $\mathrm{N}_{2}$ gas and stirring at room temperature. After thoroughly dissolved, then BTDA is added in three sequences and the addition of every sequence must be dissolved homogeneously. Continuing stirring for $2 \mathrm{~h}$ and then put in the refrigerator. The preparation procedure is worked out in Scheme 1.

\subsubsection{Synthesis of PU-prepolymer}

One equivalent weight of HTPB is added to the three necked bottle and stirred for $2 \mathrm{~h}$ to remove the residual water. Two equivalent weight of $\mathrm{H}_{12} \mathrm{MDI}$ and small amount of DBTDL are added the above reactor and stirred thoroughly. Then suitable ratio of NMP and toluene are added to $80 \mathrm{wt} . \%$ solid content and stirred reaction at $80^{\circ} \mathrm{C}$ as the $\mathrm{NCO} \%$ reaching theoretical value. The stoichiometric amount of chain extender (1,4-BD) and solvent (NMP + toluene) are then added and reacted for the theoretical NCO\% (5 wt.\%) reached. The final PU solution is with $20 \mathrm{wt} . \%$ solid content and the preparation procedure is presented in Scheme 2. 

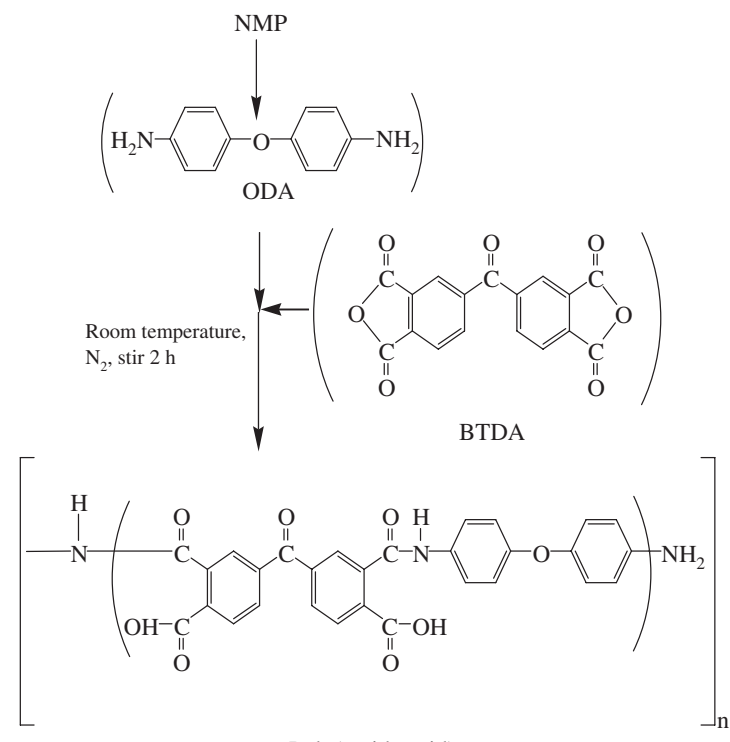

Poly(amide acid)

Scheme 1. The flow chart of the procedures to prepare the poly(amide acid).

\subsubsection{Preparation of PUI solutions}

Different weight ratio, 0.9:0.1, 0.8:0.2, 0.5:0.5 and 0.2:0.8, of PU-prepolymer and poly(amide acid) are blended respectively, which are expressed as 0.9-PUI, 0.8-PUI, 0.5-PUI and

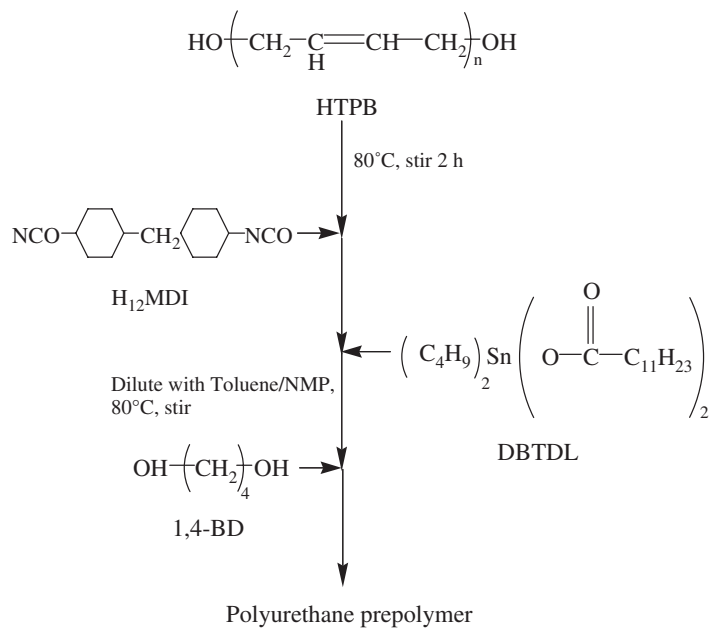

Scheme 2. Flow chart of the procedures to prepare polyurethane prepolymer.
0.2-PUI, and stirred for $2 \mathrm{~h}$ purging with $\mathrm{N}_{2}$ gas and then stored at refrigerator for usage.

\subsubsection{Preparation of PUI membranes}

Pour the above PUI solutions to the glass plate, respectively and knife coating to obtain $160 \mu \mathrm{m}$ thickness film and then put on the vacuum oven at $50^{\circ} \mathrm{C}$ for $2 \mathrm{~h}$. After most of solvent is removed and then put in circulation oven with increasing temperature programming. Through four steps of heating, thermal treatment, for imidization reaction of $\mathrm{PI}$ and reaction between PU and PI at $100^{\circ} \mathrm{C}(2 \mathrm{~h}), 150^{\circ} \mathrm{C}(2 \mathrm{~h})$, $175^{\circ} \mathrm{C}(2 \mathrm{~h})$ and $200^{\circ} \mathrm{C}(2 \mathrm{~h})$, golden and semitransparent solid films are obtained.

\subsection{Measurements}

Fourier transfer infrared spectrophotometer (FT-IR) absorption spectra are recorded between 4000 and $400 \mathrm{~cm}^{-1}$ by Nicolet PROTEGE-460. It is found that the peak due to bonded $\mathrm{C}=\mathrm{O}$ stretching is centered at about $1698 \mathrm{~cm}^{-1}$ and that due to free $\mathrm{C}=\mathrm{O}$ stretching is centered at about $1716 \mathrm{~cm}^{-1}$. The infrared absorption bands of butadiene soft segment are the trans-1,4 form at $970 \mathrm{~cm}^{-1}$, trans- 1,2 form at $912 \mathrm{~cm}^{-1}$ and cis1,4 form at $685 \mathrm{~cm}^{-1}$. The infrared absorbance of the total carbonyl groups $\left(U_{\mathrm{C}=\mathrm{O}}\right)$ detected by FTIR is calculated by the addition of the respective hydrogen bonded $\mathrm{C}=\mathrm{O}$ absorbance and free hydrogen bonded $\mathrm{C}=\mathrm{O}$ absorbance. The $U_{\mathrm{C}=\mathrm{O}} / U_{\mathrm{C}=\mathrm{C}}$ absorption peak ratio is the ratio of total $\mathrm{C}=\mathrm{O}$ absorbance with trans- 1,4 form $\mathrm{C}=\mathrm{C}$ absorbance. A larger value of this ratio indicates that larger $\mathrm{C}=\mathrm{O}$ functional groups presents on the membrane. Thermogravimetric analysis (TGA) is performed from 60 to $800^{\circ} \mathrm{C}$ with $\mathrm{Du}$ Pont TGA-950 at a heating rate of $20^{\circ} \mathrm{C} / \mathrm{min}$ and under nitrogen. The dynamic mechanical analysis (DMA) is carried out by means of thermal analyzer DMA-2980 from 60 to $300^{\circ} \mathrm{C}$, at a frequency of $1 \mathrm{~Hz}$ and heating rate of $3^{\circ} \mathrm{C} / \mathrm{min}$. 
Oxygen and nitrogen (mixed) permeabilities of the hybrid films are determined by using the Yanaco GTR-10 gas permeability analyzer. The data of gas permeabilities are the average of at least three measurements. Experiments are carried out by measuring air gas flows through the membrane under constant membrane pressure equal to $38 \mathrm{~cm} \mathrm{Hg}$. The gas permeation area is $15.6 \mathrm{~cm}^{2}$ and the gas permeability is evaluated by the following equation:

$P=\frac{q l}{(P 1-P 2) A}$

where $P$ is the $\mathrm{N}_{2}$ or $\mathrm{O}_{2}$ gas permeability $\left[\mathrm{cm}^{3}\right.$ (STP) $\left.\mathrm{cm} /\left(\mathrm{cm} \mathrm{Hg} \mathrm{cm}^{2} \mathrm{~s}\right)\right], q$ is the volumetric flow rate of gas permeation $\left[\mathrm{cm}^{3}(\mathrm{STP}) / \mathrm{s}\right], l$ is the film thickness $(\mathrm{cm}), P_{1}$ and $P_{2}$ are the upstream and downstream pressures $(\mathrm{cm} \mathrm{Hg})$ and $A$ is the effective film area $\left(\mathrm{cm}^{2}\right)$. While gas selectivity is named as the ratio of $P_{\mathrm{O}_{2}} / P_{\mathrm{N}_{2}}$ and permselectivity is the product of $P_{\mathrm{O}_{2}}$ and selectivity.

\section{Results and discussions}

\subsection{Infrared spectra}

The Fourier transfer infrared spectrophotometer spectra of pure PU, 0.8-PUI and pure PI membranes are shown in Fig. 1. The characteristic PI absorption peaks are imide asymmetrical stretching $\left(1780 \mathrm{~cm}^{-1}\right), \mathrm{C}=\mathrm{O}$ symmetrical stretching of imide $\left(1720 \mathrm{~cm}^{-1}\right), \mathrm{C}-\mathrm{N}$ stretching of imide $\left(1380 \mathrm{~cm}^{-1}\right)$ are presented. While those of PU absorption peaks are $\mathrm{N}-\mathrm{H}$ stretching (3200-3500 $\left.\mathrm{cm}^{-1}\right), \mathrm{CH}_{2}$ stretching (2900$\left.2930 \mathrm{~cm}^{-1}\right)$, and $\mathrm{C}=\mathrm{O}$ symmetrical stretching $\left(1730-1700 \mathrm{~cm}^{-1}\right)$. Fig. 2 shows the FT-IR spectra of 0.8-PUI hybrid membrane after different thermal treatment temperature. The absorption peak, $1680 \mathrm{~cm}^{-1}$, of amide acid group decreases after $175^{\circ} \mathrm{C}$ thermal treated. While the absorption peaks, at $1380,1720,1780 \mathrm{~cm}^{-1}$, of imide functional group have no any changes, which can

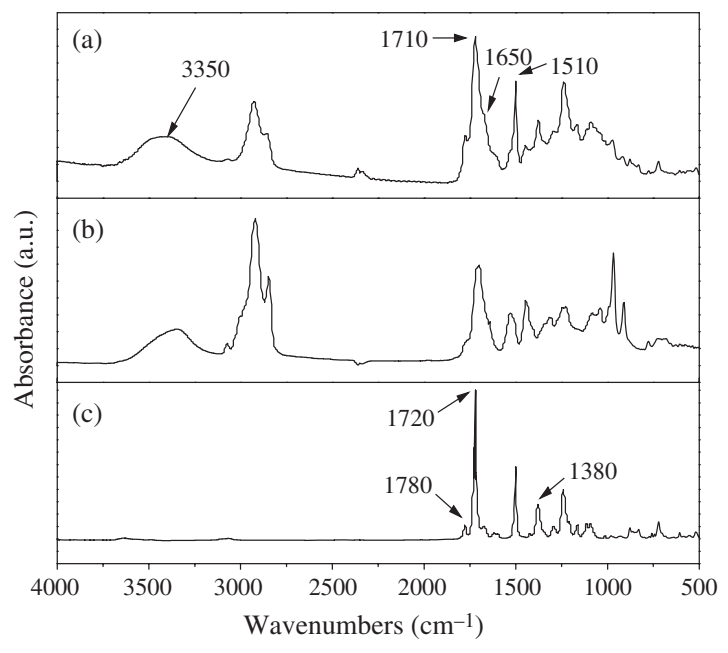

Fig. 1. FT-IR spectra of (a) pure PU, (b) 0.8-PUI and (c) pure PI membranes.

evidence that the imidization reaction has been attained completely.

While the absorption peak, at $2920 \mathrm{~cm}^{-1}$, of $\mathrm{CH}_{2}$ group of $\mathrm{PU}$ composition has a little changes. Fig. 3 shows that the $U_{\mathrm{C}=\mathrm{O}} / U_{\mathrm{C}=\mathrm{C}}$ absorption

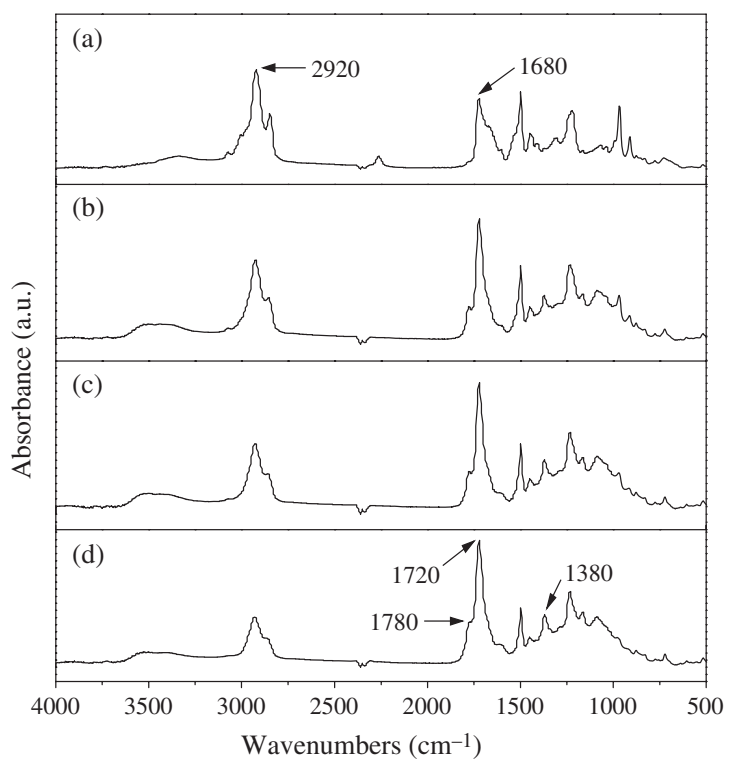

Fig. 2. FT-IR spectra of 0.8-PUI hybrid membrane at different thermal treatment temperature: (a) $100^{\circ} \mathrm{C}$, (b) $150^{\circ} \mathrm{C}$, (c) $175^{\circ} \mathrm{C}$ and (d) $200^{\circ} \mathrm{C}$. 


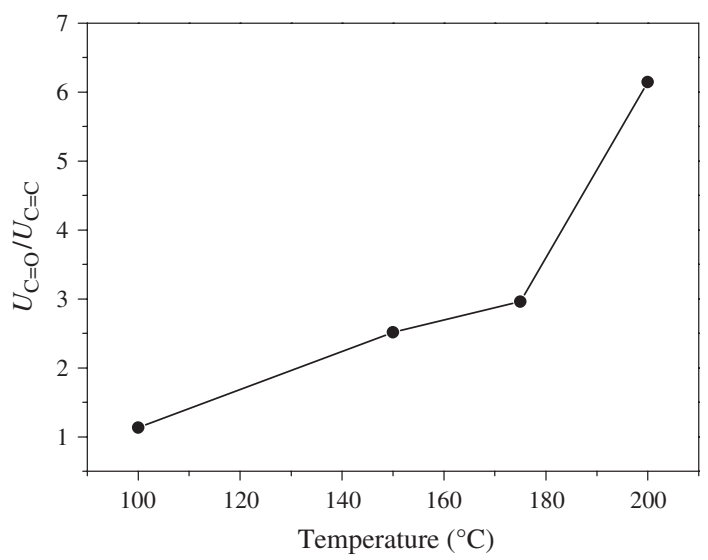

Fig. 3. Relationship between absorption ratio $U_{\mathrm{C}=\mathrm{O}} /$ $U_{\mathrm{C}=\mathrm{C}}$ and thermal treatment temperature of 0.8 -PUI membrane.

peak ratios of 0.8-PUI membrane are increased as the increase of imidization temperature and the other PUI membranes present the same trend as well. The reason is that the oxidation or broken reaction of the unsaturated $\mathrm{C}=\mathrm{C}$ double bond of HTPB polyol will be produced to form carbonyl groups or crosslinked together between different HTPB segment and hence the $\mathrm{C}=\mathrm{C}$ absorption peak decreased. Then the $U_{\mathrm{C}=\mathrm{O}} / U_{\mathrm{C}=\mathrm{C}}$ absorption peak ratios are increased as the increase of thermal treatment temperature.

\subsection{Thermal gravimetric analysis (TGA)}

A three-step degradation curves are observed. In the first step, the decomposition temperature corresponds to urethane-bond (i.e., hard segment) breaking and step 2 is the polyol decomposition (i.e., HTPB soft segment) [21,22], while step 3 corresponds to PI decomposition [23]. The thermogravimetric profile and maximum degradation temperature of PUI membranes are shown in Figs. 4 and 5 .

All the PUI hybrid and pure PU membranes show three steps weight loss and PI shows one step weight loss as shown in Fig. 4. The decomposition temperatures $\left(T_{\mathrm{d}}\right)$ are listed in Table 1.

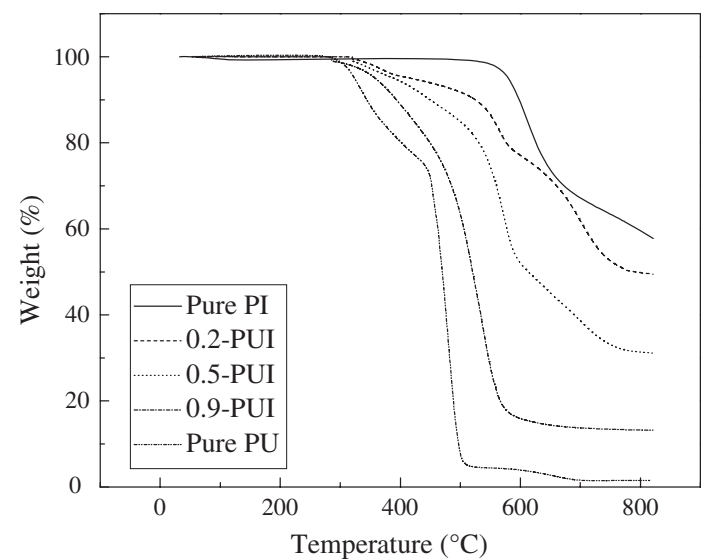

Fig. 4. Thermogravimetric curves of PUI membranes.

The 1st step decomposition temperatures of PUI membranes are nearly lower than that of pure PU. The reason may be that part of PU with free $\mathrm{NCO}$ content, which reacts with $-\mathrm{NH}$ group of amide (-CO-NH-) chain or with carboxylic acid of PI segment and hence the hydrogen bonding between PU hard segment decreased, which can be explained for the decrease of 1 st decomposition temperatures. On the other hand, the 2nd step decomposition temperatures of PUI membranes are all nearly higher than that of pure PU. The explanation is that the oxidation or broken reaction of the unsaturated double

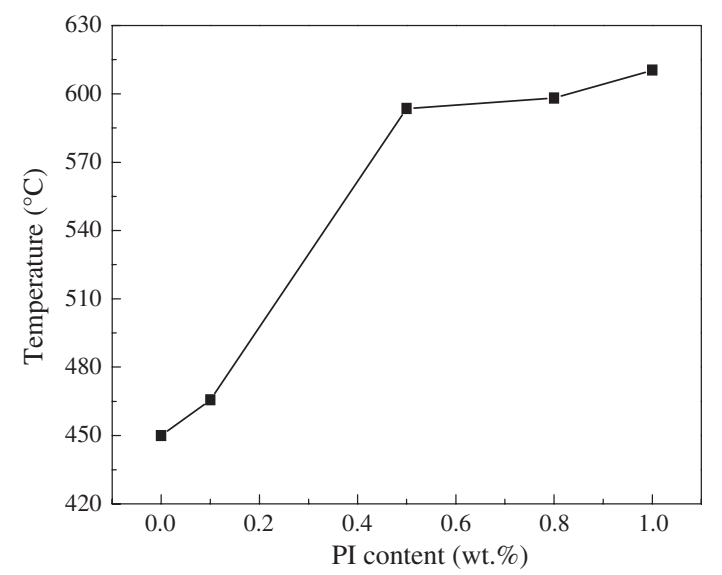

Fig. 5. Relationship between maximum degradation temperature and PI content. 
Table 1

Thermal gravimetric analysis

\begin{tabular}{lllll}
\hline $\begin{array}{l}\text { Compound } \\
\text { code }\end{array}$ & $\begin{array}{l}\text { First step } \\
\text { decomposition } \\
\text { temperature }\left({ }^{\circ} \mathrm{C}\right)\end{array}$ & $\begin{array}{l}\text { Second step } \\
\text { decomposition } \\
\text { temperature }\left({ }^{\circ} \mathrm{C}\right)\end{array}$ & $\begin{array}{l}\text { Third step } \\
\text { decomposition } \\
\text { temperature }\left({ }^{\circ} \mathrm{C}\right)\end{array}$ & Char yield $(\%)$ \\
\hline Pure PU & 300 & 450 & - & 0.2 \\
0.9 -PUI & 302.75 & 448.74 & 465.71 & 14 \\
0.5 -PUI & 229.23 & 463.45 & 593.57 & 30 \\
0.2 -PUI & 260.88 & 462.32 & 598.10 & 50 \\
Pure PI & - & - & 610.43 & 60 \\
\hline
\end{tabular}

bond of HTPB polyol will be produced to form carbonyl groups and forming intermolecular bonding between PI and PU. Meanwhile, the unsaturated $\mathrm{C}=\mathrm{C}$ double bond between different HTPB segments may be brokened and crosslinked together and then the decomposition temperature of HTPB polyol increased. Meanwhile, the 3rd step decomposition temperatures of PUI membranes are all lower than that of pure PI. The reason is that the numbers of imide ring structures of PUI are decreased, which is due to part of $\mathrm{PU}$ with free $\mathrm{NCO}$ content reacted with $-\mathrm{NH}$ group of amide $(-\mathrm{CO}-\mathrm{NH}-)$ chain or with carboxylic acid of PI segment. Then the 3rd step decomposition temperatures increase as the increase of PI content as shown in Fig. 5. Table 1 depicts that the residual after $800^{\circ} \mathrm{C}$ degradation increases as increasing the PI content also. The increase of PI content will increase the ring structures and hence needs more energy to decompose the membrane and then the residual increased. The above three decomposition temperatures changes can be collaterally used as an indication of PU dispersed in PI chain and will be discussed in Section 3.4.

\subsection{Dynamical mechanical analysis (DMA)}

The dynamic mechanical properties of PUI membranes as a function of temperature are shown in Figs. 6 and 7 and the results are summarized in Table 2. Fig. 6 shows the storage modulus of pure PI, 0.2-PUI, 0.8-PUI and 0.9-PUI membranes. It shows that the storage modulus of 0.8-PUI and 0.9-PUI, which are all with high PU content, are largely lower than pure PI and decreased to lower than $500 \mathrm{MPa}$.

While the storage modulus of PUI with high PI content at $225^{\circ} \mathrm{C}$, such as 0.2 -PUI, maintains larger than $1000 \mathrm{MPa}$. Fig. 7 shows the $\tan \delta$ curves of pure PI, 0.2-PUI, 0.5-PUI, 0.8-PUI and 0.9-PUI membranes. Aiming at $T_{\mathrm{g}}$ value of PU, the $\tan \delta$ peaks shift to higher temperature as the increase of PI content. While for the tan $\delta$ peaks of PI then shift to lower temperature and the peak intensity increased as the increase

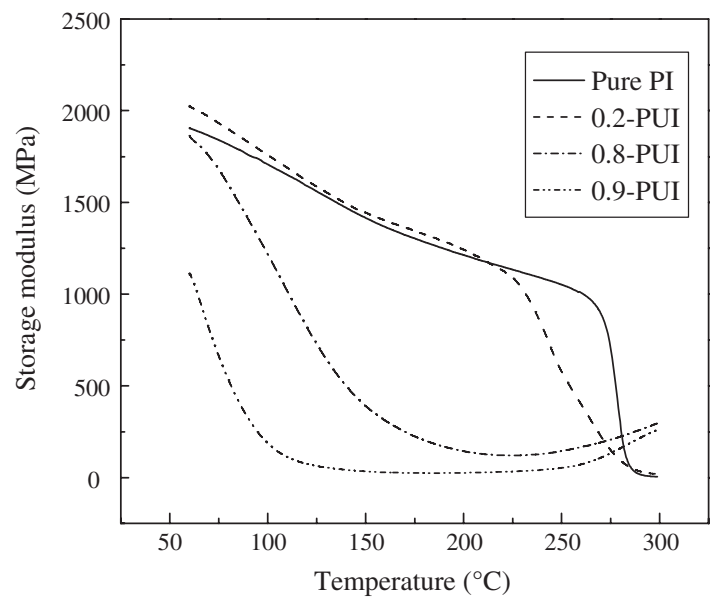

Fig. 6. Dynamic mechanical analysis of storage modulus curves. 


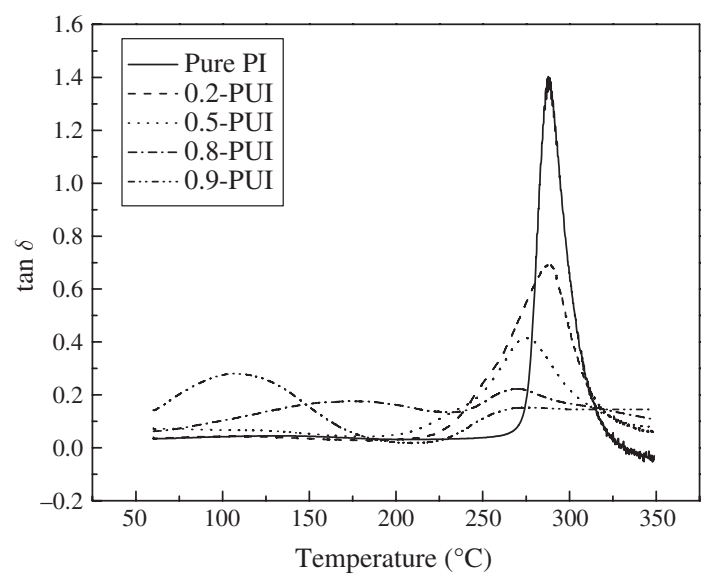

Fig. 7. Dynamic mechanical analysis of $\tan \delta$ curves.

of PU content. The storage modulus are largely decreased as the temperature is higher than $T_{\mathrm{g}}$ value and the $\tan \delta$ curves present disrupt decrease of damping loss peak.

This indicates that the damping loss peak of PUI is lower than that of pure PI membrane. The $T_{\mathrm{g}}$ values of PI part are decreased as the increase of PU content, while that of PU part are increased as the increase of PI content and disappeared from 0.5-PUI, 0.2-PUI to pure PI. The latter result may mean that the compatibility between PU, lower than $50 \mathrm{wt} . \%$ content, and PI is good.

\subsection{Morphology and order between $P U$ and PI}

The PU content in PUI hybrid may be dispersed into two parts: one is mixed with PI chain as the PU content is lower than 0.5-PUI. And as the PU content is higher than 50 wt.\%, the excess part of PU is not mixed with PI and may be dispersed on the membrane's upper layer. The explanation is that the addition of $5 \mathrm{wt} . \%$ NCO content of PU prepolymer to the polyamic acid (PAA), the free NCO content may react with $-\mathrm{NH}$ group of amide (-CO-NH-) chain to form allophanate (-CO-N(CO-NH-)-) crosslinkage at elevated temperatures $\left(100^{\circ} \mathrm{C}\right.$ or above).

The other reaction of isocyanate may with carboxylic acid of PAA proceeds usually with the formation of anhydride (-NH-CO-O-CO-) followed by decomposition, yielding the corresponding amide (-NH-CO-) with liberation of carbon dioxide at elevated temperatures $\left(100^{\circ} \mathrm{C}\right.$ or above).

The free NCO content of PU prepolymer may react with $-\mathrm{NH}$ group of amide (-CO-NH-) chain or with carboxylic acid of BTDA chain as the PU content is low as 0.2-PUI and 0.5-PUI. And then the PU polymer chains will be dispersed or entangled with the BTDA segment of PI chain, which can be evidenced from the disappearance of $\tan \delta$ temperature of 0.2-PUI,

Table 2

Dynamical mechanical properties of PUI membranes

\begin{tabular}{llll}
\hline Compound code & Storage modulus $(\mathrm{MPa})^{\mathrm{a}}$ & $\tan \delta$ of PI $\left({ }^{\circ} \mathrm{C}\right)$ & $\tan \delta$ of PU $\left({ }^{\circ} \mathrm{C}\right)$ \\
\hline Pure PU & - & - & 90 \\
0.9 -PUI & 1113 & 264.5 & 107.6 \\
0.8 -PUI & 1864 & 273.8 & 112.4 \\
0.5 -PUI & 1939 & 275.1 & $\mathrm{~b}$ \\
0.2 -PUI & 2019 & 287.4 & $\mathrm{~b}$ \\
Pure PI & 1901 & 287.8 & $\mathrm{~b}$ \\
\hline
\end{tabular}

${ }^{\mathrm{a}}$ Storage modulus are measured at $60^{\circ} \mathrm{C}$.

${ }^{\mathrm{b}}$ Peak of PU disappeared. 
0.5-PUI as depicted in Table 2. While as the PU content increased from 0.5-PUI to 0.9-PUI, part of PU content is not mixed with PI and may be dispersed on the membrane's upper layer. The above two phenomena may be collaterally evidenced from the 1st step decomposition temperatures of PUI membranes are nearly lower than that of pure PU and the 3rd step decomposition temperatures of PUI membranes are all lower than that of pure PI.

On the other hand, the unsaturated $\mathrm{C}=\mathrm{C}$ bond of HTPB may be oxidized, broken or crosslinked together at elevated temperatures $\left(100^{\circ} \mathrm{C}\right.$ or above). There have many reports about the low oxidized stability of unsaturated double bond $(\mathrm{C}=\mathrm{C})$ of HTPB segment through thermal treatment. Chiu and coworkers [24,25] have reported that the oxidation or broken reaction of the unsaturated double bond $(\mathrm{C}=\mathrm{C})$ of HTPB-based PU, under $60^{\circ} \mathrm{C}, 30$ days, does not happened. While the oxidation or broken reaction of the unsaturated double bond of HTPB will be produced to form carbonyl groups at temperature higher than $100^{\circ} \mathrm{C}$. Meanwhile, the unsaturated double bond between different HTPB segments may be crosslinked together through oxidation or broken reaction. As part of PU may be reacted with $-\mathrm{NH}$ group of amide $(-\mathrm{CO}-\mathrm{NH}-)$ chain or with carboxylic acid of PI segment. The other part of PU may be oxidized or broken between different HTPB segments to form crosslinkage. This can be collaterally evidenced from the 2nd step decomposition temperatures of PUI are all nearly higher than pure PU. Then the interpenetrating networks (IPNs) between PU and PI are formed.

\subsection{Gas separation performances}

The $\mathrm{O}_{2} / \mathrm{N}_{2}$ separation performances of HTPBbased PU membranes are all different from those of PI presented. HTPB-based PU membranes are with high gas permeability and low selectivity, while PI membranes possess the reverse results.
This study tries to blend two polymers and expects to obtain superior permeation performances.

Gases permeating through membrane are mainly through soft segment of polymer chain. From PI's chemical structure, gases are permeating through soft segments of $-\mathrm{C}(\mathrm{O})$ - group between two imide groups and - $\mathrm{O}-$ group between two benzene group. As the blend of PU and PI, the free group - NCO group may react with -NH group of amide chain or with carboxylic acid of BTDA chain and then disrupt the rigid imide chain. Then gases may permeate through the disrupted imide chain and then the gas permeability through the PI chain changed.

Table 3 depicts that the gas permeabilities of $\mathrm{O}_{2}, \mathrm{~N}_{2}$ are all increased as the increase of PU content, while the selectivities of $\mathrm{O}_{2} / \mathrm{N}_{2}$ present the reverse trend. The $\mathrm{O}_{2}, \mathrm{~N}_{2}$ gas permeability of 0.5 -PUI membrane are 23, 51 times than that of pure PI membrane, respectively, while the selectivity of $\mathrm{O}_{2} / \mathrm{N}_{2}$ is only $1 / 2$ times lower than PI membrane. As the PU content is higher than 50 wt.\%, 0.8-PUI and 0.9-PUI, the gas permeabilities and selectivities are all nearly the same as pure PU membrane. The explanations are that the free NCO content of PU prepolymer may react with $-\mathrm{NH}$ group of amide (-CO-NH-) chain or with carboxylic acid of BTDA chain as the PU content is low as 0.2-PUI and 0.5-PUI. And then the PU polymer chains will be

Table 3

$\mathrm{O}_{2}, \mathrm{~N}_{2}$ permeabilities and $\mathrm{O}_{2} / \mathrm{N}_{2}$ selectivity of pure PI, $\mathrm{PU}$ and PUI membranes at $35^{\circ} \mathrm{C}$

\begin{tabular}{llll}
\hline $\begin{array}{l}\text { Compound } \\
\text { code }\end{array}$ & $\begin{array}{l}P_{\mathrm{O}_{2}} \\
\text { (Barrer) }\end{array}$ & $\begin{array}{l}P_{\mathrm{N}_{2}} \\
(\text { Barrer })\end{array}$ & $P_{\mathrm{O}_{2}} / P_{\mathrm{N}_{2}}$ \\
\hline Pure PU & 22.8 & 11.9 & 1.92 \\
0.9 -PUI & 20.1 & 10.2 & 1.97 \\
0.8 -PUI & 17.2 & 7.82 & 2.20 \\
0.5 -PUI & 3.65 & 1.07 & 3.41 \\
0.2 -PUI & 0.25 & 0.054 & 4.63 \\
Pure PI & 0.16 & 0.021 & 7.62 \\
\hline
\end{tabular}


dispersed or entangled with the BTDA segment of PI chain. While as the PU content increased from 0.5-PUI to 0.9-PUI, the imide chain of PI will be entangled and destructed more seriously. Then the gas permeabilities and selectivities of 0.5-PUI-0.9 PUI membranes are nearly the same as that of PU membrane. This may be the reason for there has a disrupt change at 0.5 -PUI for the gas permeability and selectivities.

\section{Conclusion}

The absorption peak, $1680 \mathrm{~cm}^{-1}$, of amide acid group of PI chain decreases after $175^{\circ} \mathrm{C}$ thermal treated. The $U_{\mathrm{C}=\mathrm{O}} / U_{\mathrm{C}=\mathrm{C}}$ absorption peak ratios of 0.8 -PUI membrane are increased as the increase of imidization temperature due to the oxidation reaction of the unsaturated double bond $(\mathrm{C}=\mathrm{C})$ of HTPB segment and the other PUI membranes present the same trend as well. The 1st step decomposition temperatures of PUI membranes are nearly lower than that of pure PU. On the other hand, the 2nd step decomposition temperatures of PUI membranes are all nearly higher than that of pure PU. Meanwhile, the 3rd step decomposition temperatures of PUI membranes are all lower than that of pure PI. While the residual after $800^{\circ} \mathrm{C}$ degradation increases as increasing PI content. The $T_{\mathrm{g}}$ values of PI part are decreased as the increase of PU content, while $T_{\mathrm{gh}}$ of PU part are increased as the increase of PI content and disappeared from 0.5-PUI, 0.2-PUI to pure PI. The latter result may mean that the compatibility between PU and PI is good as the PU content is lower than $50 \mathrm{wt} . \%$. As part of PU may be reacted with - NH group of amide (-CO-NH-) chain or with carboxylic acid of PI segment. The other part of $\mathrm{C}=\mathrm{C}$ groups of PU may be oxidized or broken between different HTPB segments to form crosslinkage. Then the interpenetrating networks (IPNs) between PU and PI are formed. PU content may be dispersed into two parts: one is mixed with PI chain as the PU content is lower than 0.5-PUI. The other is that as the PU content is higher than 0.5-PUI, part of PU is not mixed with PI and may be dispersed on the membrane's upper layer.

\section{Acknowledgements}

The authors would like to express their appreciation to the National Science Council of the Republic of China for this study under grant NCS-96-2622-E-167-001-CC3 and U-Best Polymer Industry Company for the financial support.

\section{References}

[1] M. Moadebb and W.J. Koros, Gas transport properties of thin polymeric membranes in the presence of silicon dioxide particles, J. Membr. Sci., 125 (1997) 143-163.

[2] K. Kusakabe, K. Ichiki, J. Hayashi, H. Maeda and S. Morooka, Preparation and characterization of silica-polyimide composite membranes coated on porous tubes for $\mathrm{CO}_{2}$ separation, J. Membr. Sci., 115 (1996) 65-75.

[3] K. Okamoto, K. Noborio, J. Hao, K. Tanaka and H. Kiya, Permeation and separation properties of polyimide membranes to 1,3-butadiene and n-butane, J. Membr. Sci., 134 (1997) 171-179.

[4] M. Smaihi, J.C. Schrotter, C. Lesimple, I. Prevost and C. Guizard, Gas separation properties of hybrid imide-siloxane copolymers with various silica contents, J. Membr. Sci., 161 (1999) 157-170.

[5] S.H. Chen, M.H. Lee and J.Y. Lai, Polysiloxaneimide membranes: gas transport properties, Eur. Polym. J., 32 (1996) 1403-1408.

[6] L.S. Teo and C.Y. Chen, The gas transport properties of amine-containing polyurethane and poly(urethane-urea) membranes, J. Membr. Sci., 141 (1998) 91-99.

[7] S.H. Chen, K.C. Yu, S.L. Huang and J.Y. Lai, Gas transport properties of HTPB based polyurethane/ cosalen membrane, J. Membr. Sci., 173 (2000) 99-106.

[8] S.L. Huang and J.Y. Lai, HTPB-H $\mathrm{H}_{12}$ MDI based polyurethane IPN membranes for pervaporation, J. Membr. Sci., 115 (1996) 1-10. 
[9] J.M. Yang, H.T. Lin and W.C. Lai, Properties of modified hydroxyl-terminated polybutadiene based polyurethane membrane, J. Membr. Sci., 208 (2002) 105-117.

[10] D. Yong and B. Bikson, Soluble aromatic polyamides containing the phenylindane group and their gas transport characteristics, Polymer, 43 (2002) 4709-4714.

[11] S.L. Huang, R.C. Ruaan and J.Y. Lai, Gas permeability of cupric ion containing HTPB based polyurethane membranes, J. Membr. Sci., 123 (1997) 71-79.

[12] S.L. Huang and J.Y. Lai, On the gas permeability of hydroxyl terminated polybutadiene based polyurethane membranes, J. Membr. Sci., 105 (1995) 137-145.

[13] A.K. Mishra, D.K. Chattopadhyay, B. Sreedhar and K.V.S.N. Raju, Thermal and dynamic mechanical characterization of polyurethane-urea-imide coatings, J. Appl. Polym. Sci., 102 (2006) 3158-3167.

[14] T. Takeichi, K. Ujiie and K. Inoue, High performance poly(urethane-imide) prepared by introducing imide blocks into the polyurethane backbone, Polymer, 46 (2005) 11225-11231.

[15] H. Yeganeh and M.A. Shamekhi, Poly(urethaneimide-imide), a new generation of thermoplastic polyurethane elastomers with enhanced thermal stability, Polymer, 45 (2004) 359-365.

[16] A.K. Mishra, D.K. Chattopadhyay, B. Sreedhar and K.V.S.N. Raju, FT-IR and XPS studies of polyurethane-urea-imide coatings, Prog. Org. Coat., 55 (2006) 231-243.

[17] D.K. Chattopadhyay, A.K. Mishra, B. Sreedhar and K.V.S.N. Raju, Thermal and viscoelastic properties of polyurethane-imide/clay hybrid coatings, Polym. Degrad. Stab., 91 (2006) 1837-1849.

[18] H. Behniafar, S. Haghighat and S. Farzaneh, Direct synthesis of soluble and thermally stable poly(urethane-imide)s from a new triimide-dicarbonylazide, Polymer, 46 (2005) 4627-4634.

[19] H. Deligöz, T. Yalcinyuva and S. Özgümüs, A novel type of Si-containing poly(urethane-imide)s: synthesis, characterization and electrical properties, Eur. Polym. J., 41 (2005) 771-781.

[20] M. Awkal, A. Jonquieres, R. Clement and P. Lochon, Synthesis and characterization of film-forming poly(urethaneimide) cationomers containing quaternary ammonium groups, Polymer, 47 (2006) 5724-5735.

[21] P.D. Nair, M. Jayabalam and V.N. Krishramurthy, Polyurethane-polyacrylamide IPNs. I. Synthesis and characterization, J. Polym. Sci. Part A: Polym. Chem., 28 (1990) 3775-3783.

[22] S.L. Huang, P.H. Chang, M.H. Tsai and H.C. Chang, Properties and pervaporation performances of crosslinked HTPB-based polyurethane membranes, Sep. Purif. Technol., 56 (2007) 63-70.

[23] M.H. Tsai, P.C. Chiang, W.T. Whang and S.L. Huang, Synthesis and characteristics of polyimide/siloxane hybrid films for reliability adhesion, Surface Coating Technol., 200 (2006) 3297-3302.

[24] T.M. Don, W.Y. Chiu and K.H. Hsieh, Thermal aging of filled polyurethane, J. Appl. Polym. Sci., 43 (1991) 2193-2199.

[25] T. Gupta and B. Adhikari, Thermal degradation and stability of HTPB-based polyurethane and polyurethaneureas, Thermochim. Acta, 402 (2003) 169-181. 